\title{
Prediction of mortality in hospital survivors of myocardial infarction \\ Comparison of predischarge exercise testing and radionuclide ventriculography at rest
}

\author{
P FIORETTI, R W BROWER, M L SIMOONS, S K DAS, $R$ J BOS, W WIJNS, J H C REIBER, \\ J LUBSEN, P. G HUGENHOLTZ
}

From the Thoraxcenter, the Department of Nuclear Medicine, Erasmus University and University Hospital Dijkzigt, Rotterdam; the Interuniversity Cardiology Institute, Amsterdam, The Netherlands; and the `Division of Cardiology, University of Michigan, USA

SUMMARY The relative merits of resting ejection fraction measured by radionuclide angiography and predischarge exercise stress testing were compared for predicting prognosis in hospital survivors of myocardial infarction. Two hundred and fourteen survivors of myocardial infarction out of 338 consecutive patients with acute myocardial infarction were studied over a 14 month period. Hospital mortality was $13 \%$ (45 of 338) whereas 19 additional patients out of 214 died in the subsequent year (9\%). High, intermediate, and low risk groups could be identified by left ventricular ejection fraction measurement. Mortality was $33 \%$ for nine patients with an ejection fraction $<20 \%, 19 \%$ for 58 patients with an ejection fraction between $20 \%$ and $39 \%$, and $3 \%$ for 147 patients with an ejection fraction $>40 \%$. Mortality was high (23\%) in 47 patients who were unable to perform the stress test because of heart failure (19) or other limitations (28). The patients could be stratified further into intermediate and low risk groups according to the increase in systolic blood pressure during exercise: six deaths occurred in 46 patients with a blood pressure increase of $<30 \mathrm{~mm} \mathrm{Hg}$ and two deaths occurred in 121 patients with an increase $\geqslant 30 \mathrm{~mm} \mathrm{Hg}$. Maximum workload, angina, ST changes, and ventricular arrhythmias were less predictive than blood pressure changes.

It is concluded that the prognostic value of radionuclide angiography at rest and of symptom limited exercise testing is similar. The latter investigation should be the method of choice since it provides more specific information for patient management.

The identification of high risk and low risk subjects among those who have recovered from acute myocardial infarction remains a major aim in clinical practice. Prognostic stratification can be based on variables related to left ventricular dysfunction, the extent of coronary artery disease, residual myocardial ischaemia, or ventricular arrhythmias. ${ }^{1-3}$ Adequacy of left ventricular function can be judged from clinical signs $^{4} 5$ or can be quantified by non-invasive or inva-

Requests for reprints to Dr Paolo Fioretti, Erasmus University, Thoraxcenter, Dr Molewaterplein 40, 3015 GD Rotterdam, The Netherlands.

Accepted for publication 17 April 1984 sive methods such as haemodynamic monitoring, ${ }^{16}$ radionuclide studies, ${ }^{27}$ echocardiography, ${ }^{8}$ or cardiac catheterisation. ${ }^{39}$ Residual ischaemia can be shown by exercise stress testing ${ }^{10-12}$ and ventricular arrhythmias can be detected by ambulatory electrocardiographic monitoring ${ }^{13}$ or provocative electrophysiological testing. ${ }^{14}$ Based in part on these observations, it has been suggested that an algorithm may be developed to identify patients at highest risk, in whom more aggressive management would be indicated. ${ }^{15}$ Such an algorithm should use the most sensitive and specific tests and eliminate those that are costly and redundant. Little information is available, however, on the relative predictive value of various investigations. 
In this prospective study of hospital survivors of myocardial infarction we compared the relative power of predischarge clinical evaluation, symptom limited exercise testing, and radionuclide angiography at rest for predicting late mortality.

\section{Patients and methods}

The records of 338 consecutive patients admitted to the coronary care unit of the Thoraxcenter between 1 March 1981 and 30 April 1982 with documented acute myocardial infarction were reviewed. A diagnosis of myocardial infarction was made if at least two of the following criteria were present: $(a)$ typical prolonged chest pain of at least 45 minutes; $(b)$ dynamic electrocardiographic changes defined, in case of transmural infarction, as evolving $Q R$ complexes or $Q$ waves $\geqslant 0.04 \mathrm{~s}$ with $S T$ and $T$ wave changes or in the case of non-transmural infarction as $\mathrm{T}$ wave inversion or ST depression persisting for at least $\mathbf{2 4}$ hours without loss of $R$ wave voltage or new $Q$ waves (the site was defined as undetermined in cases of complete left bundle branch block); and (c) a typical rise and fall in total creatine kinase with a peak concentration $\geqslant 100$ IU/1 (twice the upper limit of normal values in our laboratory). Previous infarction was diagnosed by a history of documented myocardial infarction or diagnostic $Q$ wave abnormalities.

Included in this series were 48 patients with complicated myocardial infarction who were referred from neighbouring hospitals. During the initial hospital admission 45 patients died, 22 of whom were referred because of complications. Complete data for the present study were available for 214 patients. Twenty one patients who underwent coronary artery bypass graft surgery or percutaneous transluminal coronary angioplasty before discharge and 59 patients who did not undergo radionuclide angiography because of early referral to another hospital or in whom for logistic reasons complete data could not be obtained were excluded from this follow up study.

The baseline clinical characteristics of the patients, both with and without radionuclide angiographic data including sex, prevalence of previous infarction, site of the index infarction, and Killip class during admission to the coronary care unit, were comparable. The median hospital stay was 13 days (range 7-78 days). Treatment in the acute phase was guided by haemodynamic monitoring with a Swan-Ganz catheter in 139 patients according to the guidelines recently described. ${ }^{16}$ Thirty eight patients were treated with intracoronary streptokinase, as part of an ongoing randomised trial. ${ }^{17}$ Metoprolol 50 or $100 \mathrm{mg}$ twice daily was given when indicated by angina or hypertension and also as a general secondary preventive agent provided that there were no contraindications or side effects. ${ }^{18}$

Before discharge radionuclide angiography was performed in the $45^{\circ}$ left anterior oblique view after in vivo labelling of the red blood cells with $15 \mathrm{mCi}$ ( 540 $\mathrm{MBq}$ ) of technetium-99m. Acquisition was performed during a six minute period with a Searle Phogamma V camera of a Siemens cardiac camera equipped with a low energy all purpose collimator. The data were processed through an automated contour detector with correction for background activity, and left ventricular ejection fraction was computed from the end systolic and end diastolic images. 19

A symptom limited exercise test with stepwise increments of $10 \mathrm{~W} / \mathrm{min}$ was performed on a bicycle ergometer before discharge in 167 of the 214 patients. Three Frank leads were constantly recorded and analysed by a computer system. ${ }^{20}$ Cuff blood pressure was obtained at two minute intervals during exercise and in the recovery phase. All clinically prescribed medication was maintained during the test.

After hospital discharge all patients returned to the outpatient clinic at two weeks, 12 weeks, six months, and 12 months. One year follow up was complete.

\section{STATISTICAL ANALYSIS}

Univariate analysis with unpaired Student's $t$ test for continuous variables, and the $\chi^{2}$ or Fisher's exact test when appropriate was applied for the discrete variables. The most advantageous cut off points for continuous variables were selected from receiver-operator characteristics curves. In these curves the specificity vs sensitivity of a test are plotted, where sensitivity is the fraction of positive classifications for all patients who in fact satisfy the end point criteria, and specificity is the fraction of all negative classifications for all patients who in fact satisfy the non-end point criteria. These curves, when generated for different tests, provide a direct comparison of the various test results over the entire range of measurements. The major end point of interest in this study was mortality in the follow up period, although other end points such as reinfarction and occurrence of angina pectoris were also studied.

\section{Results}

\section{CLINICAL FOLLOW UP}

Complete data including radionuclide angiograms were available in 214 patients. Nineteen of these 214 patients died during follow up (9\%). Eight died within one month of discharge (six suddenly and two of progressive heart failure), seven between one and six months (all suddenly), and four between six and 12 months (two suddenly, one of a fatal reinfarction, one of progressive heart failure). In addition, of those 58 patients who were excluded from the study because 
of incomplete predischarge data, eight patients died. In the latter group patients were on average four years older than the 214 patients in the study, but they did not differ as regards history of previous infarction, location of infarction, or Killip class as determined in the coronary care unit. No patient was lost to follow up.

After discharge 31 (14\%) patients had clinical signs or symptoms of heart failure. In $82(38 \%)$ angina pectoris occurred, which in 17 was treated by coronary artery bypass surgery or coronary angioplasty. Three ( $1.4 \%)$ patients developed episodes of sustained ventricular tachycardia and 19 (9\%) a non-fatal reinfarction.

\section{MORTALITY PREDICTION BY PREDISCHARGE CLINICAL DATA}

The specificity and sensitivity for the prediction of late mortality of clinical variables recorded during hospital stay after the first $\mathbf{4 8}$ hours of admission or at discharge are shown in Table 1 . The variables indicating left ventricular dysfunction, such as clinical signs of heart failure, a cardiothoracic ratio $>50 \%$, and the need for digitalis or diuretics at discharge, were all

Table 1 Specificity and sensitivity of clinical data obtained during hospital admission at least 48 hours after admission or at discharge for predicting mortality $(n=214)$

\begin{tabular}{lll}
\hline & $\begin{array}{l}\text { Sensitivity } \\
(\%)\end{array}$ & $\begin{array}{l}\text { Specificity } \\
(\%)\end{array}$ \\
\hline Late sustained ventricular & & \\
$\quad$ tachycardia or fibrillation & 21 & 98 \\
Angina & 31 & 81 \\
Heart failure & 58 & 82 \\
Cardiothoracic ratio $(>50 \%)$ & 58 & 80 \\
Treatment with: & 75 & 78 \\
Digitalis & 68 & 66 \\
Diuretics & & \\
\hline
\end{tabular}

more predictive than angina. In addition, nonsurvivors were older (mean (SD) age 62 (11) vs 56 (10) years; $p<0.005)$ and more often had had a previous myocardial infarction $(p<0.005)$.

\section{EXERCISE TEST AND LATE MORTALITY}

A symptom limited exercise test was performed by 167 out of 214 patients. Forty seven patients were unable to undergo the exercise test: seven patients because of general disability (all $>70$ years), 19 because of persistence of clinical signs of heart failure, three because of angina, and 18 because of noncardiac limitations. These patients were older than those who could be exercised (mean (SD) age 65(9) vs $54(10)$ years; $p<0.001$ ), more often had a history of previous myocardial infarction $(38 \%$ vs $24 \%$; p < 0.05$)$, were more symptomatic ( $19 \%$ vs $4 \%$ in Killip class III or IV; $\mathbf{p}<0.002$ ), and had a lower ejection fraction at discharge (mean (SD) $40 \%(16 \%)$ vs $49 \%$ $(13 \%) ; p<0.0005)$. Eleven of the $47(23 \%)$ patients with contraindications for the stress test died. Nine of these 11 non-survivors had evident heart failure and two non-cardiac limitations. Eight of the 167 patients who performed the test did not survive during follow up ( $5 \%$ mortality). This made inability to perform the stress test the strongest predictor of late mortality $(p<0.0005)$. It correctly predicted $58 \%$ of nonsurvivors with contraindications (sensitivity $58 \%$ ) and $82 \%$ of survivors without contraindications (specificity 82\%). Table 2 summarises the stress test results, and in Fig. 1 these data are presented as receiver-operator characteristics curves. From the various measurements during the stress test the most sensitive predictor of mortality was an inadequate rise in systolic blood pressure during exercise (Fig. 1). All non-survivors had a pressure rise of $<45 \mathrm{~mm} \mathrm{Hg}$. Although the appearance of ventricular tachycardia during the stress test was also significantly associated

Table 2 Results of stress test in relation to late mortality. Values are mean (I SD) unless stated otherwise

\begin{tabular}{llll}
\hline & Survivors $(n=159)$ & Non-suvivors $(n=8)$ & $P$ value \\
\hline $\begin{array}{l}\text { Maximum workload (W) } \\
\text { \% Maximum work capacity }\end{array}$ & $116(33)$ & $98(31)$ & NS \\
Heart rate (beats/min): & $79(17)$ & $75(18)$ & NS \\
Resting & $83(16)$ & $94(26)$ & NS \\
Maximum & $135(23)$ & $150(28)$ & 0.05 \\
Systolic pressure (mm Hg): & $121(16)$ & $128(24)$ & NS \\
Resting & $166(28)$ & $148(23)$ & 0.05 \\
Maximum & $45(24)$ & $20(15)$ & 0.005 \\
Rise & $47(29)$ & $2(25)$ & NS \\
No (\%) of patients with: & $57(36)$ & $5(62)$ & NS \\
Angina & $70(44)$ & $4(50)$ & NS \\
ST depression & $100(63)$ & $7(87)$ & NS \\
ST elevation & $35(22)$ & $3(37)$ & NS \\
Any ST changes & $11(7)$ & $2(25)$ & $<0.02$ \\
Any ventricular extrasystoles & $2(1)$ & $1(14)$ & \\
Ventricular couplets & & & \\
Ventricular tachycardiat & & & \\
\hline
\end{tabular}

$\star \geqslant 1 \mathrm{~mm}$.

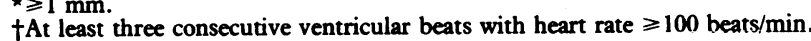




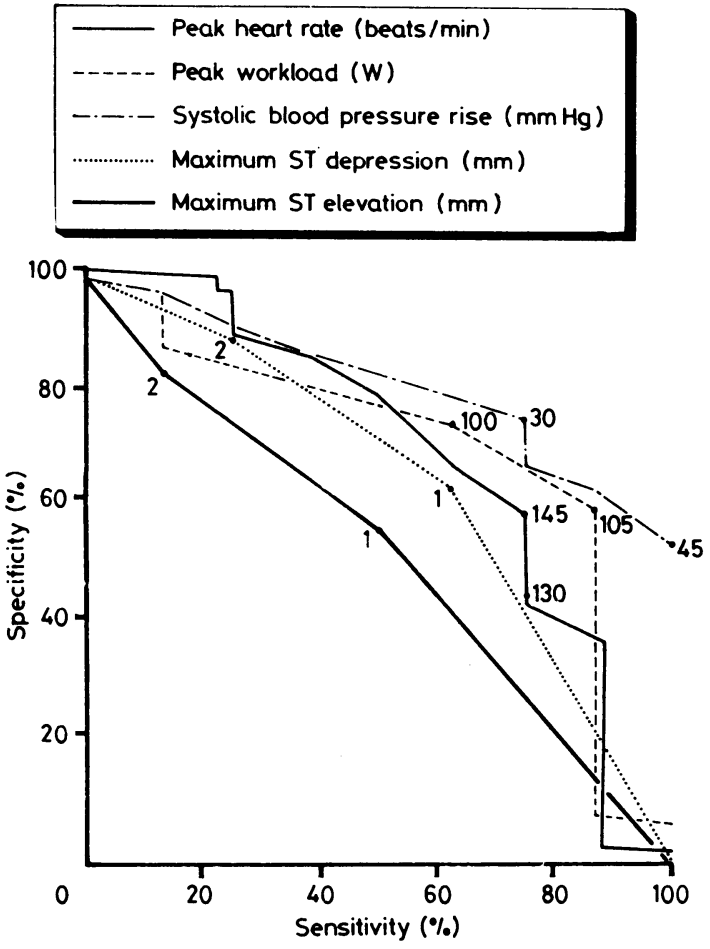

Fig. 1 Specificity vs sensitivity for late mortality of exercise testing derived data.

with late mortality, its sensitivity was low at $12 \%$. Fig. 2 shows the distribution of the systolic blood pressure change during the exercise stress test. By using as cut off point for risk stratification the contraindication for stress testing or a systolic blood pressure rise of $<30 \mathrm{~mm} \mathrm{Hg}$, three groups at high, intermediate, and low risk were identified with a respective mortality of $23 \%, 13 \%$ and $2 \%$ (Table 3 ).

\section{RADIONUCLIDE ANGIOGRAPHY AND LATE MORTALITY}

Left ventricular ejection fraction was measured by radionuclide angiography in all 214 patients. Fig. 3

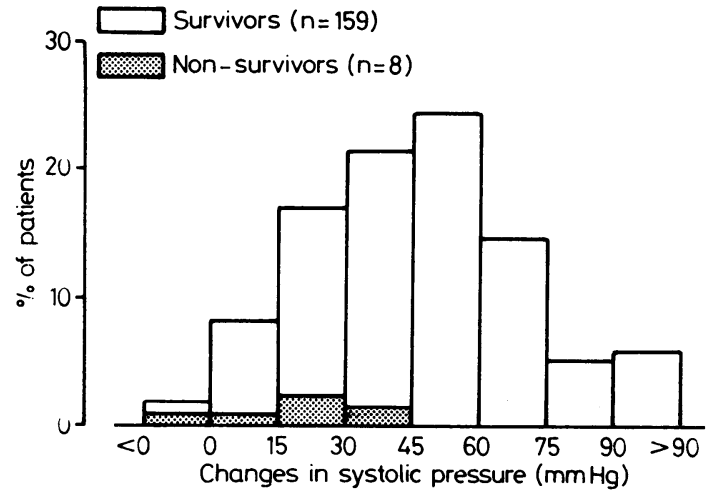

Fig. 2 Frequency distribution of systolic blood pressure change during exercise testing in survivors and non-survivors.

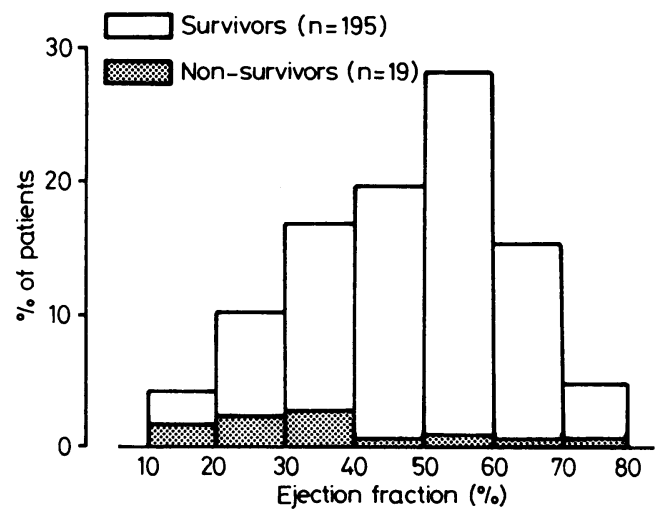

Fig. 3 Frequency distribution of ejection fraction by radionuclide ventriculography in survivors and non-survivors.

shows the distribution of ejection fraction and the respective mortality. Ejection fractions were lower in non-survivors than in survivors $(35 \%(16 \%)$ vs $48 \%$ $(14 \%) ; p<0.0005)$. Nevertheless, five patients died who had had a moderately reduced or normal ejection fraction at discharge (mean (SD) $40 \%(16 \%)$ vs $49 \%$ $<20 \%$ ), intermediate risk (ejection fraction $20-39 \%$ ),

Table 3 Characterisation of high, intermediate, and low risk groups by exercise testing and radionuclide ventriculography in relation to mortality. Figures are numbers of patients unless otherwise stated

\begin{tabular}{lcccc}
\hline & Survivors $(n=195)$ & Non-survivors $(n=19)$ & Total & Mortality (\%) \\
\hline Systolic blood pressure: & & Exercise testing & \\
$\quad$ No test performed & 36 & 11 & 47 & 23 \\
Rise <30 mm Hg & 40 & 6 & 46 & 13 \\
Rise $\geqslant 30 \mathrm{~mm} \mathrm{Hg}$ & 119 & 2 & 121 & \\
& & & & \\
Ejection fraction (\%): & 6 & Radionuclide ventriculography & & \\
$\quad<20$ & 47 & 3 & 58 & 19 \\
$20-39$ & 142 & 5 & 147 & 3 \\
$\geqslant 40$ & & & & \\
\hline
\end{tabular}


and low risk (ejection fraction $\geqslant 40 \%$ ) groups were identified with a respective mortality of $33 \%, 19 \%$, and $3 \%$ (Table 3 ).

\section{Discussion}

The fate of hospital survivors of myocardial infarction has been related to the extent of left ventricular dysfunction, ${ }^{1-3}$ the extent of coronary artery disease, ${ }^{39}$ signs of residual myocardial ischaemia, ${ }^{10}$ or the presence of ventricular arrhythmias. ${ }^{1314}$ The relative merits of the different tests have not yet, however, been fully explored. This study focuses on the value of predischarge exercise testing and resting radionuclide angiography in predicting one year survival since both tests are in common use. Our results indicate that measurement of ventricular function either at rest or during stress carries the most prognostic information. Ventricular tachycardia occurred infrequently, although those who had such arrhythmias during inhospital monitoring or exercise have a high risk of mortality (one out of three patients with ventricular tachycardia during the stress test died). The predictive value for one year survival or mortality of angina or ST changes during exercise was low (Table 1, Fig. 1). The best predictors were clinical data relating to left ventricular function such as heart failure, treatment with digitalis (Table 1), and contraindications for a predischarge stress test (Table 3 ) as well as direct measurement of left ventricular ejection fraction at rest (Table 3, Fig. 3) and the blood pressure rise during exercise, which is a measure of left ventricular function during stress ${ }^{21} 22$ (Fig. 2, Table 3).

The present data on left ventricular ejection fraction agree with other reports. ${ }^{92324}$ For example, Schulze et al found a $30 \%$ mortality during one year follow up in 26 patients with an ejection fraction $<40 \%$ and no mortality in the 55 patients who had an eiection fraction $>40 \% .{ }^{23}$ Sanz et al reported a $22 \%$ mortality rate at four years in patients with three vessel coronary artery disease and an ejection fraction between $21 \%$ and $40 \%$ but a very low mortality (between $0 \%$ and $4 \%$ ) in patients with an ejection fraction $>50 \% .{ }^{9}$ The highest mortality occurred in patients with a resting ejection fraction $<20 \%$. Similarly, we found a $33 \%$ mortality when the resting ejection fraction was $<20 \%$, a $19 \%$ mortality with an ejection fraction between $20 \%$ and $39 \%$, and only a $3 \%$ mortality when the ejection fraction exceeded $40 \%$ (Table 3 ).

A predischarge submaximal or symptom limited exercise test 10-20 days after recovery from myocardial infarction is safe and is predictive of future cardiac events, ${ }^{3} 1024$ even though Pedersen et al reported four patients out of 1500 who had serious arrhythmias, one of whom died.21 The occurrence of angina pectoris, ST depression, and the lack of an appropriate blood pressure response reflect diffuse coronary artery disease 3222526 with a worsening prognosis in those who have all three signs.

In our experience an inadequate blood pressure response was the best predictor of late mortality followed by a reduction in the maximal workload (Fig. 1 and Table 2). Consistent with these results are those of Jennings et al, who recently reported that poor exercise haemodynamics-such as peak heart rate higher than 130 beats/min or a reduction in systolic blood pressure-were more often associated with late mortality than ST changes. ${ }^{27}$

The low predictive value of exercise induced ST segment changes, in contrast to the original report of Theroux et al, 28 could be due to the use of a different lead system, although there is no reason to question the use of the Frank three lead system for this purpose. Indeed Theroux found a lower incidence of ST depression (30\%) than that in the present study (44\%) despite mortality being greater ( $14 \%$ vs $9 \%)$. The use of beta blockers at the time of the test was similar ( $39 \%$ vs $43 \%$ ) in both studies. The percentage of patients with ST depression during exercise in our study was similar in those with and without beta blockade ( $42 \%$ and $47 \%$ respectively).

In our study no significant correlation was found between the extent of rise in blood pressure and the resting ejection fraction in individual patients. This apparent negative result is not surprising since left ventricular dysfunction due to myocardial ischaemia can often be detected only during increased myocardial oxygen demand.

Coronary arteriography was performed in 66 patients who underwent a predischarge stress test. In accordance with earlier reports, multivessel disease was found in $51 \%$ of patients $(n=26)$ with a blood pressure rise $>30 \mathrm{~mm} \mathrm{Hg}$, whereas $74 \%(n=12)$ of patients with a lower blood pressure rise had multivessel disease.

We confirm, therefore, that both resting radionuclide angiography and exercise testing are predictive of mortality. Their relative predictive value can be derived from receiver-operator characteristics curves of both methods. For the purpose of this comparison a contraindication for stress testing should be included as the worst outcome of that test (Fig. 4). The large overlap between the curves of the two methods suggest that the predictive value of the two tests is similar, even if the results have to be regarded with some caution owing to the small number of end points.

The risk classification of the individual patients by the two methods was best when the extent of blood pressure rise and subsequent mortality were compared. There were only two deaths in the 121 patients with a blood pressure rise of $>30 \mathrm{~mm} \mathrm{Hg}$ compared 


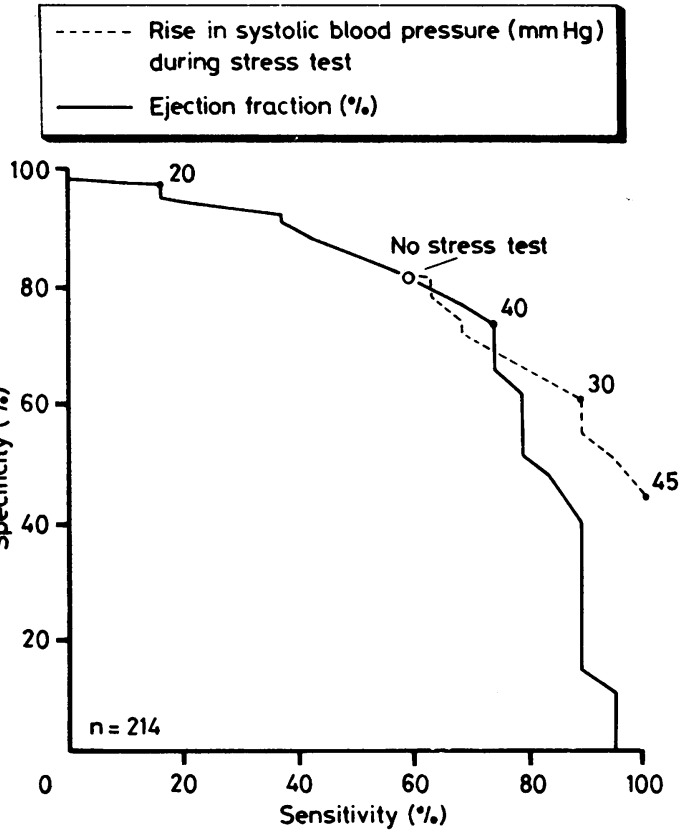

Fig. 4 Specificity os sensitivity for late mortality of exercise testing (contraindication or change of systolic pressure during the test) and radionuclide ventriculography.

with six in the 46 with a lower blood pressure rise (Table 3).

Moreover, in the 85 patients who had a blood pressure rise of $\geqslant 45 \mathrm{~mm} \mathrm{Hg}$, no late deaths occurred. Most importantly, in the three patients whose death had not been predicted by resting radionuclide angiography, since their ejection fraction was $>40 \%$, the blood pressure rise was $<30 \mathrm{~mm} \mathrm{Hg}$. Death in these patients with normal or moderately impaired left ventricular function could have been due to a severe proximal multivessel coronary disease, as suggested by the poor blood pressure response during exercise.

In summary, we find that a simple measurement- the extent of blood pressure rise during bicycle exercise testing just before discharge-has a predictive value for late mortality which is at least comparable to that of resting radionuclide ventriculography in hospital survivors of myocardial infarction. Our results suggest that a poor systolic pressure rise during exercise may indicate severely depressed left ventricular function as well as extensive coronary artery disease in the presence of normal or moderately depressed ventricular function at rest. Accordingly, we have constructed an algorithm for evaluating patients after myocardial infarction (Fig. 5). An exercise test should be performed in all patients without contraindications. Those patients without angina and with an adequate blood pressure response during exercise can be discharged without further studies since these have an excellent prognosis with medical treatment. Radionuclide angiography could be used to evaluate left ventricular function at rest in those patients who cannot be exercised because of heart failure or general disability and in patients with a poor blood pressure response during exercise. Coronary angiography should be limited to patients with postinfarction angina, to patients with an inadequate blood pressure response during exercise, or to patients with heart failure. In the latter group left ventricular function should not be too severely compromised (left ventricular ejection fraction $>20 \%$ ).

Others have proposed reliance on resting radionuclide angiography in all patients after myocardial infarction. ${ }^{15}$ In our opinion the guidelines in Fig. 5 are preferrable in practice because exercise testing is less expensive and has similar prognostic value to that of radionuclide angiography. In addition, the exercise test provides information on arrhythmias, myocardial ischaemia, and exercise tolerance, which can be used in the management of individual patients after myocardial infarction.

We thank our many colleagues in the cardiac catheterisation laboratory: in particular, $\mathrm{Dr} \mathrm{M}$ vd Brand and

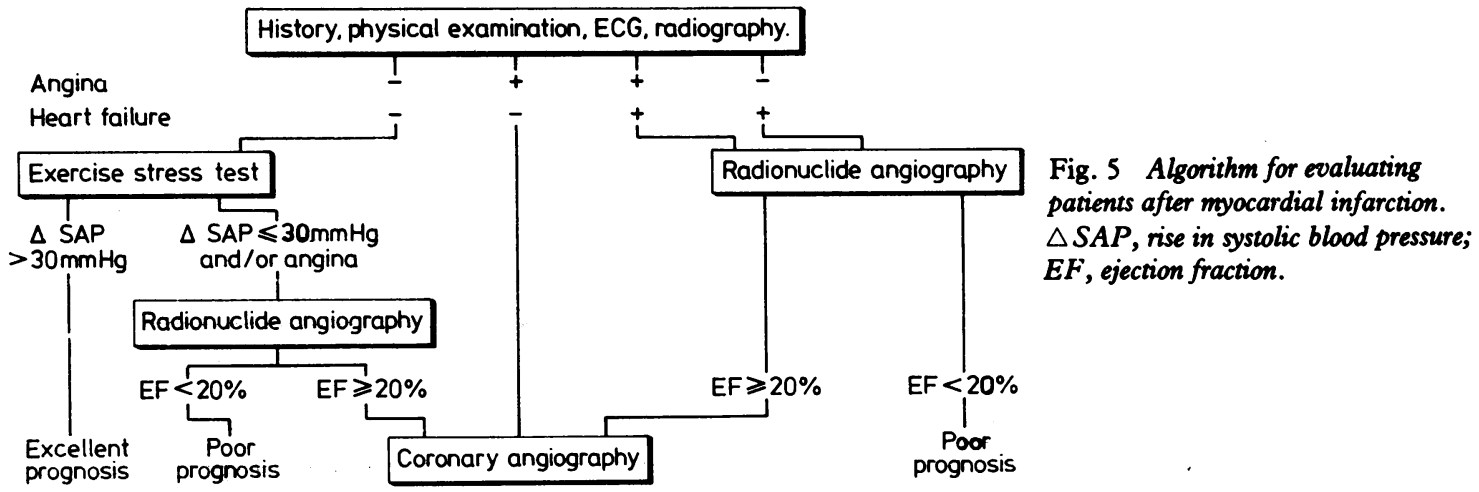


Dr P W Serruys, who performed coronary angiography, coronary angioplasty, and thrombolysis on some of the patients reported here, $\mathrm{H}$ Wolf, who assisted in the establishment of the data bank used in this study, and $\mathrm{K}$ van Dijvendijk, who performed most of the nuclear studies.

\section{References}

1 Wolffenbuttel BHR, Verdouw PD, Scheffer MG, Bom HPA, Bijleveld RE, Hugenholtz PG. Significance of haemodynamic variables in coronary care unit for prediction of survival after acute myocardial infarction. $\mathrm{Br}$ Heart f 1983; 50: 266-72.

2 The Multicenter Postinfarction Research Group. Risk stratification after myocardial infarction. $N$ Engl $\mathcal{F}$ Med 1983; 309: 331-6.

3 De Feyter PJ, van Eenige MJ, Dighton DH, Visser FC, de Jong J, Roos JP. Prognostic value of exercise testing, coronary angiography and left ventriculography 6-8 weeks after myocardial infarction. Circulation 1982; 66: 527-36.

4 Killip T, Kimball JT. Treatment of myocardial infarction in a coronary care unit: a two year experience with 250 patients. Am $\mathcal{Y}$ Cardiol 1967; 20: 457-64.

5 Norris RM, Caughey DE, Mercer CJ, Scott PJ. Prognosis after myocardial infarction-six years follow-up. $\mathrm{Br}$ Heart $\mathcal{F}$ 1974; 36: 786-90.

6 Verdouw PD, Hagemeijer F, van Dorp WG, van der Vorm A, Hugenholtz PG. Short-term survival after acute myocardial infarction predicted by hemodynamic parameters. Circulation 1975; 52: 413-9.

7 Perez-Gonzales J, Botvinick EH, Dunn R, et al. The late prognostic value of acute scintigraphic measurement of myocardial infarction size. Circulation 1982; 66: 960-71.

8 Gibson RS, Bishop HL, Stamm RB, Crampton RS, Beller GA, Martin RP. Value of early two dimensional echocardiography in patients with acute myocardial infarction. Am f Cardiol 1982; 49: 1110-9.

9 Sanz G, Castañer A, Betriu A, et al. Determinants of prognosis in survivors of myocardial infarction. A prospective clinical angiographic study. $N$ Engl $f$ Med 1982; 306: $1065-70$.

10 Miller DH, Borer JS. Exercise testing after myocardial infarction. Risks and benefits. Am F Med 1982; 72: 42738.

11 Corbett JR, Dehmer GJ, Lewis SE, et al . The prognostic value of submaximal exercise testing with radionuclide ventriculography before hospital discharge in patients with recent myocardial infarction. Circulation 1981; 64: $535-44$.

12 Dewhurst NG, Muir AL. Comparative prognostic value of radionuclide ventriculography at rest and during exercise in 100 patients after first myocardial infarction. $\mathrm{Br}$ Heart $\mathcal{F}$ 1983; 49: 111-21.

13 Bigger JT Jr, Weld FM, Rolnitzky LM. Prevalence, characteristics and significance of ventricular tachycardia (three or more complexes) detected with ambulatory electrocardiographic recording in late hospital phase of acute myocardial infarction. Am $\mathcal{F}$ Cardiol 1981; 48: $815-23$.

14 Richards DA, Cody DV, Denniss AR, Russell PA, Young AA, Uther JB. Ventricular electrical instability: a predictor of death after myocardial infarction. $\mathrm{Am} \mathcal{F} \mathrm{Car}$ diol 1983; 51: 75-80.

15 Epstein SE, Palmeri ST, Patterson RE. Evaluation of patients after acute myocardial infarction. Indications for cardiac catheterization and surgical intervention. $N$ Engl f Med 1982; 307: 1487-92.

16 Simoons ML, Serruys PW, Fioretti P, van den Brand M, Hugenholtz PG. Practical guidelines for treatment with betablockers and nitrates in patients with acute myocardial infarction. Eur Heart $\mathcal{F}$ 1983; 4 (suppl D): 129-35.

17 Fioretti P, Simoons ML, Serruys PW, van den Brand M, Fels PW, Hugenholtz PG. Clinical course after attempted thrombolysis in myocardial infarction. Results of pilot studies and preliminary data from a randomized trial. Eur Heart f 1982; 3: 422-32.

18 Chamberlain DA. Beta adrenoceptor antagonists after myocardial infarction-where are we now? Br Heart $\mathcal{f}$ 1983; 49: 105-10.

19 Reiber JHC, Lie SP, Simoons ML, et al. Clinical validation of fully automated computation of ejection fraction from gated equilibrium blood-pool scintigrams. $\mathcal{F} \mathrm{Nucl}$ Med 1983; 24: 1099-107.

20 Simoons ML, Hugenholtz PG. Estimation of the probability of exercise induced ischemia by quantitative ECG analysis. Circulation 1977; 56: 552-9.

21 Pederson A, Grande P. Saunamäki K, Schaadt O. Exercise testing after myocardial infarction [Letter]. $N \mathrm{Engl} F$ Med 1980; 302: 174.

22 Morris SN, Phillips JF, Jordan JW, McHenry PL. Incidence and significance of decreases in systolic blood pressure during graded treadmill exercise testing. $\mathrm{Am} \mathcal{F}$ Cardiol 1978; 41: 221-6.

23 Schulze RA Jr, Strauss HW, Pitt B. Sudden death in the year following myocardial infarction. Relation to ventricular premature contractions in the late hospital phase and left ventricular ejection fraction. Am $\mathcal{f}$ Med 1977; 62: $192-9$.

24 Betriu A, Castañer A, Sanz GA, et al. Angiographic findings 1 month after myocardial infarction: a prospective study of 259 survivors. Circulation 1982; 65: 1099 105.

25 Levites R, Baker T, Anderson GJ. The significance of hypotension developing during treadmill exercise testing. Am Heart $\mathcal{F}$ 1978; 95: 747-53.

26 Starling MR, Crawford MH, Richards KL, O'Rourke RA. Predictive value of early postmyocardial infarction modified treadmill exercise testing in multivessel coronary artery disease detection. Am Heart $\mathcal{f}$ 1981; 102: $169-75$.

27 Jennings K, Reid DS, Julian DG. Role of early postinfaction exercise test in identifying candidates for early coronary surgery [Abstract]. Br Heart $\mathcal{F}$ 1983; 49: 289.

28 Théroux P, Waters DD, Halpen C, Debaisieux JC, Mizgala HF. Prognostic value of exercise testing soon after myocardial infarction. $N$ Engl f Med 1979; 301: 341-5. 